\title{
Analisis Kualitas Bonding Cement Di Zona Produktif Sumur BA 147 Menggunakan Ultra Sonic Imager Tool (USIT) Log di Lapangan BOB PT Bumi Siak Pusako-Pertamina Hulu
}

\author{
Fitrianti $^{1}$ \\ ${ }^{1}$ Program Studi Teknik Perminyakan Universitas Islam Riau
}

\begin{abstract}
Abstrak
Squeeze cementing adalah bagian dari pekerjaan ulang sumur yang bertujuan untuk memperbaiki kualitas bonding cement yang buruk. Kualitas bonding cement yang buruk dapat menyebabkan meningkatnya harga water cut akibat masuknya fluida yang tidak diinginkan ke dalam sumur seperti air dan gas . Terjadinya High Water Cut pada Sumur BA\#147 hingga 99\% diikuti penurunan oil rate hingga 8.97 bopd yang signifikan menjadi suatu permasalahan. Hal ini dikarenakan oleh masalah terbatasnya fasilitas pengolahan air dan pertimbangan efisiensi produksi. Sehingga perlu dilakukan evaluasi kualitas bonding cement dan squeeze cementing disekitar zona produktif sumur BA\#147. Metode analisis kualitas bonding cement yang digunakan yaitu Ultra Sonic Imager Tool (USIT). USIT mampu menginterpretasikan kondisi cement, casing dan jenis material (liquid dan gas) yang terdapat dibelakang casing. Selanjutnya dilakukan design squeeze cementing untuk meningkatkan kualitas bonding cement yang buruk. Setelah dilakukan analisis berdasarkan hasil image impedance yang diinterpretasikan USIT, didapatkan hasil kualitas bonding cement yang buruk pada interval kedalaman 3300ft - 3380ft. Berdasarkan hasil interpretasi USIT tersebut dilakukan squeeze cementing untuk memperbaiki bonding cement. Dibutuhkan 8.55 slurry cement, $1.27 \mathrm{bbl}$ additive dan maximum squeeze pressure 586 psi. Teknik penyemenan yang digunakan yaitu teknik penyemenan bradenhead (open ended). Kualitas cement setelah dilakukan squeeze cementing pada sumur BA\#147 yaitu good bonding berdasarkan harga image impedance yang ditampilkan pada rekaman USIT kedua.
\end{abstract}

Kata Kunci: Squeeze cementing, Water cut, USIT, Bradenhead, Bonding cement

Alamat email korespondensi penulis: fitrianti@eng.uir.ac.id

\section{PENDAHULUAN}

Squeeze cementing adalah bagian dari pekerjaan ulang sumur yang bertujuan menutup lubang perforasi yang sudah ada dan untuk memperbaiki bonding cement yang buruk (George,K, 1998-1998). Pada pekerjaan penutupan perforasi, squeeze cementing bertujuan untuk memindahkan interval yang tidak ekonomis lagi ke interval baru yang lebih ekonomis. Untuk pekerjaan channeling yang dapat menyebabkan masuknya fluida yang tidak diinginkan tersebut ke dalam sumur. Selain dapat menyebabkan korosi pada casing, channeling yang juga dapat menyebabkan produksi sumur menjadi High Water Cut, dikarenakan fluida air yang menembus zona produktif melalui kerusakan bonding cement yang saling terhubung.

Langkah selanjutnya setelah squeeze cementing adalah melakukan penilaian (evaluasi) terhadap hasil operasi tersebut. Prosedur ini dilaksanakan untuk mengetahui sejauh mana keberhasilan pelaksanaan squeeze cementing, apakah sudah sesuai dengan tujuan operasi. Metode yang umum digunakan untuk mengevaluasi hasil penyemenan dapat menggunakan cement bond $\log (C B L)$. Namun pada penelitian ini, $\log$ yang dibahas untuk menginterpretasikan bonding cement dibelakang casing adalah USIT log, dimana log ini mempunyai kelebihan dari CBL. USIT log dapat menginterpretasikan gambaran kualitas semen secara $360^{\circ}$ serta dapat mengevaluasi kerusakan casing. USIT log biasa digunakan jika hasil CBL tidak memenuhi cut-off good bonding yang kemungkinan disebabkan karena adanya microannulus. 
Tujuan utama evaluasi hasil penyemenan dengan menggunakan rekaman USIT log adalah melihat jenis material dan kualitas semen dibelakang casing. Apabila ada sebagian annulus yang tidak terisi penuh oleh semen sehingga terbentuk channeling atau microannulus, maka penyemenan dikatakan gagal, sehingga fluida yang tidak diinginkan seperti air dan gas akan masuk ke dalam sumur.

Pada penelitian ini, penulis akan mengamati kualitas bonding cement di zona produktif sumur BA\#147 yang mengalami peningkatan water cut dan penurunan oil rate secara signifikan. Metode evaluasi penyemenan yang digunakan dalam penelitian ini yaitu dengan menggunakan USIT. Berdasarkan hasil rekaman USIT log, bonding cement dinyatakan baik apabila memberikan nilai impedansi yang besar atau image impedansi yang berwarna gelap. Sedangkan bonding cement dinyatakan buruk apabila memberikan nilai impedansi yang kecil atau image impedansi yang berwarna terang.

\section{METODE PENELITIAN}

Pada penelitian ini, peneliti langsung melakukan riset lapangan (field research) pada BOB PT BSP Pertamina-Hulu dan mengadakan wawancara dengan pihak-pihak yang dianggap berkepentingan dalam masalah yang akan dibahas. Data primer yang digunakan berupa data history well completion, data produksi, data hasil proses logging. Data sekunder yang digunakan pada penelitian ini antara lain adalah data laboratorium untuk design semen dan zat additive yang digunakan.

\section{Penentuan Cadangan}

Salah satu metode yang dapat digunakan untuk menghitung cadangan minyak (OOIP) menggunakan persamaan volumetrik. Metode ini digunakan jika terdapat data geologi, data log, dan data core dengan persamaan Original Oil In Place (OOIP), jumlah total minyak mula-mula yang terdapat didalam suatu reservoir sebelum reservoir tersebut diproduksikan dengan persamaan:

$$
\text { OOIP }=\frac{7758 \times A \times H \times[\times(1-S w]}{\text { Bo }} \text { STB }
$$

\section{Hasil Interpretasi USIT}

USIT membaca material yang berada dibelakang casing berdasarkan nilai impedansi yang dihasilkan. Impedance images ini dapat digunakan untuk mengidentifikasi patahan dalam formasi atau cacat internal kecil dalam casing. Berikut adalah kriteria impedance images yang ditampilkan oleh USIT:

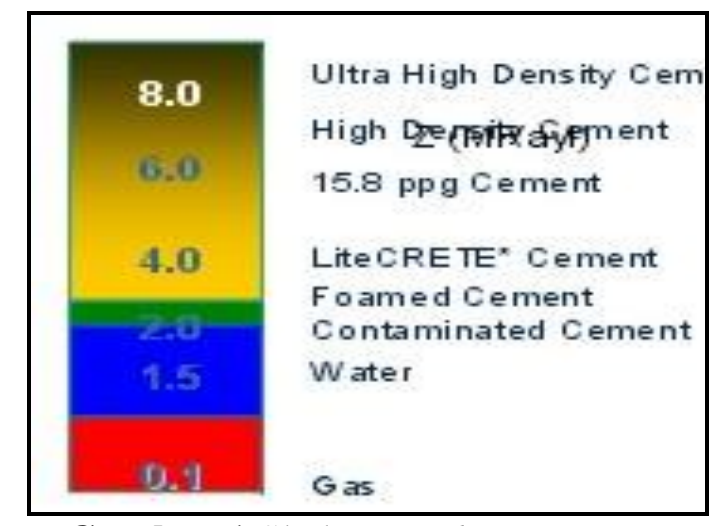

Gambar 1 Skala impedance images 
Linear color scale

- Putih $<0.5$ MRayl= Tidak ada semen.

- Kuning - Coklat merupakan langkah dari 0.5 MRayl.

- Black $<8$ MRayl = Good cement .

Dengan tampilan thresholds

- $\quad$ Merah < 0.3 MRayl = gas instrusi (dari formasi gas atau gas yang ikut terproduksi)

Pada foam cement.

- $\quad$ Biru $<2.6$ MRayl = fluid - water

or mud in cement

- $\quad$ Kuning $<3$ MRayl = foam cement

or very contaminated neat cement

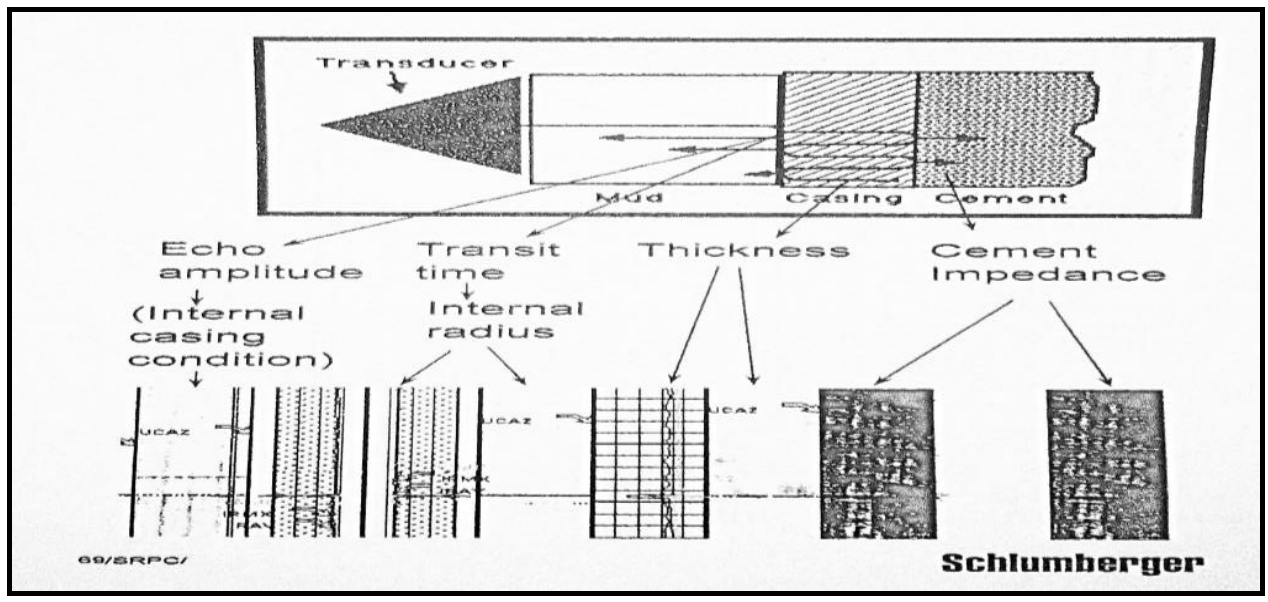

Gambar 2 USIT measurement (Andrew Hayman, 2000)

Saat beroperasi alat USIT harus terpusat di tengah-tengah pada fluida yang terisi dalam lubang bor, yang berada di bawah dalam kombinasi apapun. Operasi USIT dibatasi oleh faktor-faktor seperti kepadatan lumpur tinggi dan gas terlarut yang meningkatkan redaman pulsa akustik alat ini saat melewati cairan lubang bor (Javier Paynere,2003).

USIT menyediakan banyak informasi tentang di kedua lubang open hole dan case hole. Di lubang terbuka, USIT memberikan informasi mengenai lubang bor lengkap untuk evaluasi formasi yang tepat akurat. Di case hole, ultrasonik inspeksi pipa dan evaluasi semen sekarang dapat diperoleh secara bersamaan. 


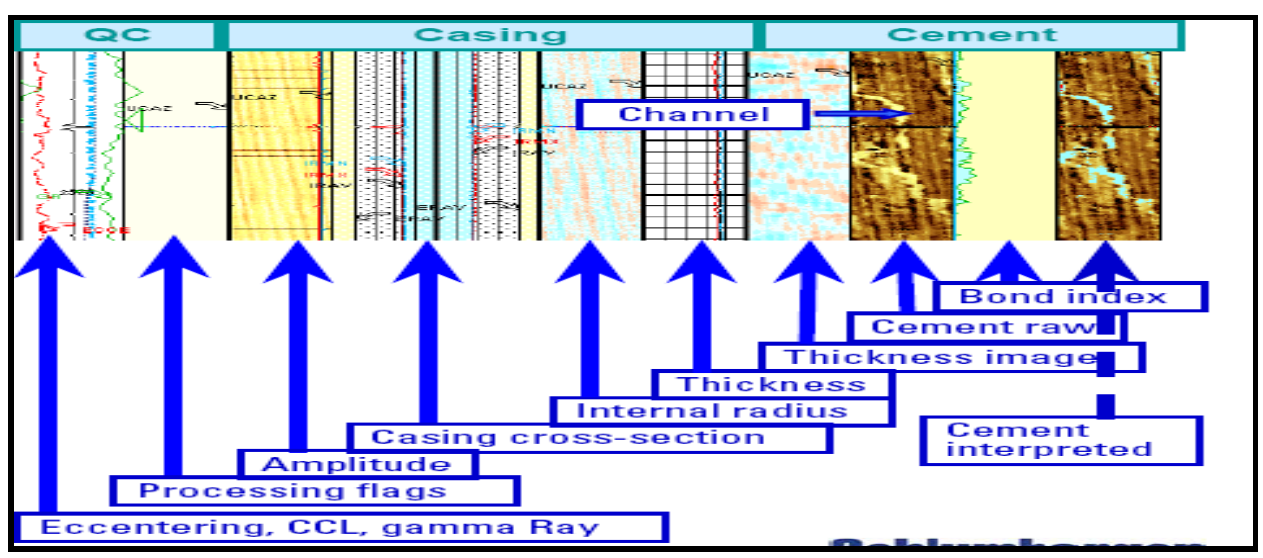

Gambar 3 USIT map interpretation (Javer Peynere, 2003)

Berdasarkan Gambar 3, presentasi semen evaluasi termasuk casing ovality, alat eksentrisitas dan gamma ray terdapat pada track 1. Dan untuk processing flags terdapat pada track 2. Pada Track 3 terdapat harga amplitudo dari casing yang menggambarkan kondisi internal casing. Pada track 4, 5, dan 6 memberikan gambaran mengenai casing cross - section. Pada track 7 dan 8 menggambarkan amplitudo dan kondisi internal radius dari casing. Track 9 menggambarkan kondisi cement raw. Track 10 menggambarkan kondisi bonding cement dibelakang casing. Dan track 11 menggambarkan image impedansi dari kualitas bonding cement (thresolds).

\section{Secondary Cementing}

Secondary cementing yaitu proses penyemenan yang dilakukan untuk menutup kembali zona produksi yang diperforasi ataupun memperbaiki proses penyemenan pada saat primary cementing yang tidak berhasil. Secondary cementing dapat dibagi menjadi tiga bagian, yaitu: squeeze cementing, $R e$ cementing dan Plug-back cementing.

a. Squeeze cementing

Squeeze cementing dilakukan untuk:

1. Menutup formasi yang sudah tidak lagi produktif

2. Menutup zona lost circulation

3. Memperbaiki kebocoran yang terjadi di casing

b. Re-cementing

Re-Cementing dilakukan untuk menyempurnakan primary cementing yang gagal dan untuk memperluas perlindungan casing di atas top semen.

c. Plug-back cementing

Plug-back cementing dilakukan untuk:

1. Menutup atau meninggalkan sumur

2. Menutup zona air di bawah zona minyak agar water-oil ratio berkurang pada open hole completion.

Sebelum mencampur slurry, injectivity zona harus diketahui dulu dengan memompa 3 sampai 5 barrel air untuk memeriksa tekanan dan komunikasi. Jangan sampai terjadi rekahan pada proses ini. Akan sangat baik jika ditest dahulu tekanan sirkulasi balik (reverse circulation) pada kecepatan tertentu 
sebelum penyemenan. Tambahkan pada tekanan sirkulasi balik ini, perbedaan tekanan hidrostatik antara total volume slurry didalam pipa dan fluida workover di annulusnya.

\section{Injectivity Test}

Injectivity test merupakan faktor yang sangat berpengaruh dalam menentukan keberhasilan pekerjaan squeeze cementing, sebab dengan melakukan injectivity test didapat informasi tentang daerah yang akan di squeeze, diantaranya apakah formasi masih sanggup menerima fluida, berapa tekanan pemompaan bubur semen dan design bubur semen. Berikut adalah parameter hasl injectivity test:

a. Loose injection profile, Tekanan injektivitas $<50$ psi.

b. Moderate injection profile, Tekanan injectivitas antara 50 to 200 psi.

c. Tight injection profile, Tekanan injektivitas $>200 \mathrm{psi}$

\section{Teknik-Teknik squeeze cementing}

\section{Block Squeezing}

Block Squeeze adalah suatu teknik perbaikan primary cementing dengan menambah perforasi casing di atas atau di bawah interval produksi kemudian meng-squeezekan semen melalui perforasi tersebut untuk menempatkan semen pada chanel-chanel tersebut. Teknik block squeezing ini dapat dilihat pada Gambar 4 berikut.

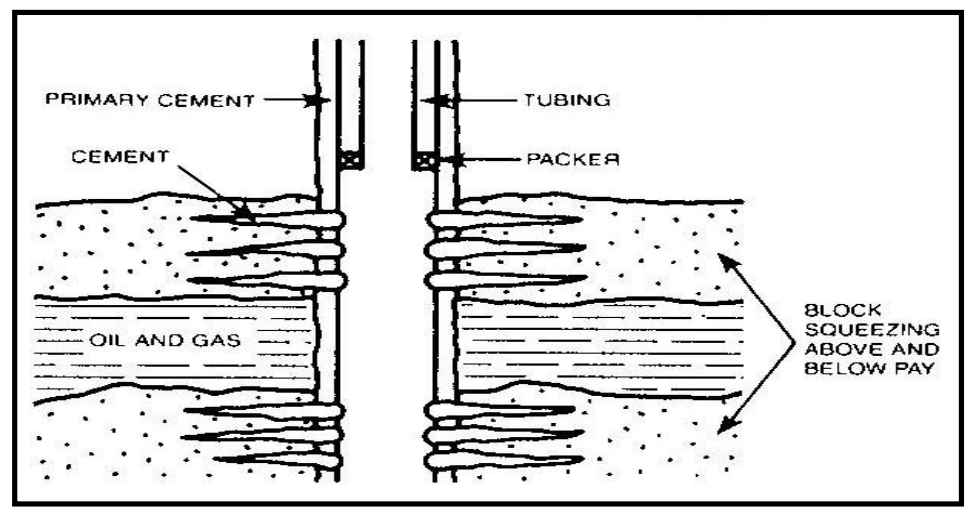

Gambar 4 Block Squeezing (Nelson, 1990)

\section{Bullhead Squeezing}

Teknik penyemenan ini dengan menempatkan bubur semen mulai dari permukaan sampai ke perforasi dalam lubang sumur. Dalam hal ini biasanya digunakan bottom plug dan top plug. Metoda ini sangat jarang dilakukan karena sulitnya mengontrol penempatan bubur semen di dalam lubang sumur. Jika terjadi problem di dalam operasi ini tidak ada cara apapun untuk mensirkulasikan kembali bubur semen tersebut dari lubang sumur. Kerugiannya, dari casing dan seluruh fluida yang ada dalam lubang akan terdorong kembali ke formasi dimana fluida ini berada didepan dari sumur semen yang dipompakan tadi. 


\section{Brandenhead squeeze}

Metode ini ialah menggunakan teknik penempatan bubur semen ke depan lubang perforasi dengan memompakan bubur semen melalui rangkaian atau string. Dalam operasi lapangan, metode penyemenan bradenhead lebih dikenal dengan nama open ended squeeze. seperti pada (Gambar 5)

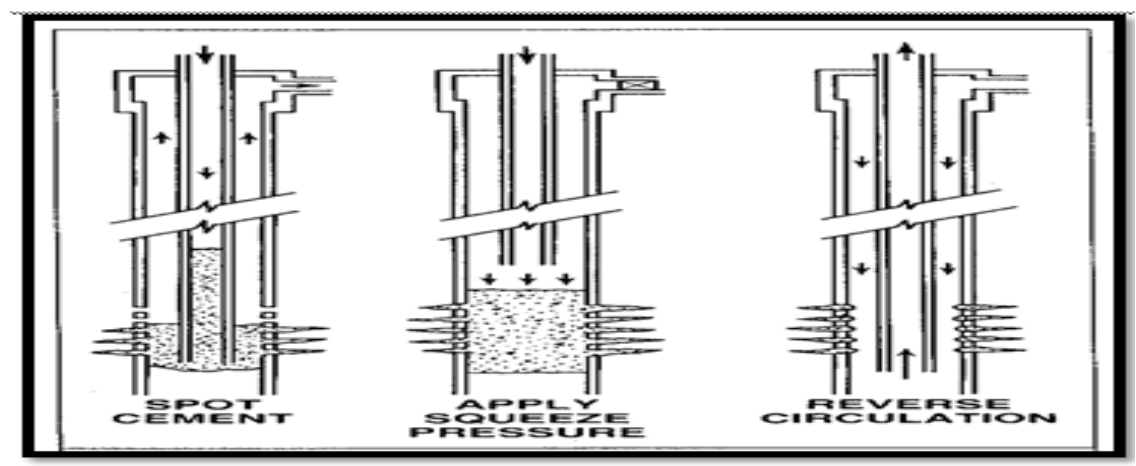

Gambar 5 Bradenhead Squeezing (Nelson, 1990)

\section{Packer Squeeze}

Teknik penyemenan ini dilakukan dengan cara menggunakan packer yang dapat diambil kembali (retrievable packer) atau bisa juga dengan menggunakan sebuah semen retainer.

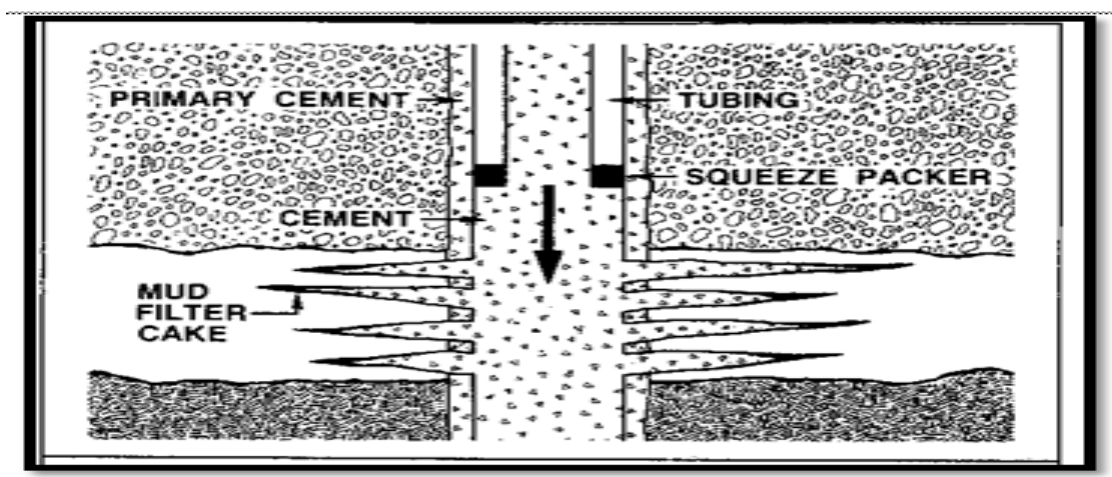

Gambar 6 Packer Squeeze (Nelson, 1990)

\section{HASIL DAN PEMBAHASAN}

Lapangan Zamrud terdiri dari 2 lapisan reservoir yaitu lapisan Bekasap (Bekasap 2830' Sand' dan Bekasap 2900' Sand) dan lapisan Bangko (Bangko 2970' Sand dan Bangko 3050' Sand). Sumur BA\#147 hanya diproduksikan dari lapisan reservoir Bekasap 2830' Sand yang memiliki 31' probable oil dan 12 possible oil. Dan Bekasap 2900' Sand yang memiliki 2' possible oil dan 4 probable oil. Sedangkan untuk lapisan reservoir Bangko 2970' Sand dan 3050' Sand tidak diproduksikan karena berdasarkan marked log untuk sumur BA\#147, pada lapisan reservoir Bangko 2970' Sand dan 3050' Sand tidak teridentifikasi adanya cadangan. Untuk memastikan hal ini dapat dilihat gambar dibawah ini pada (Gambar 7), yang menunjukkan data logging untuk sumur BA\#147. 
Sumur BA\#147 mulai diproduksikan sejak tahun 2001 pada interval perforasi 3278' - 3288', 3294 3308, dan 3360'-3370'. Sumur BA\#147 telah beberapa kali dilakukan kerja ulang sumur (workover) hingga tahun 2014 dengan kumulatif produksi minyak sebesar 619.796 bbl.

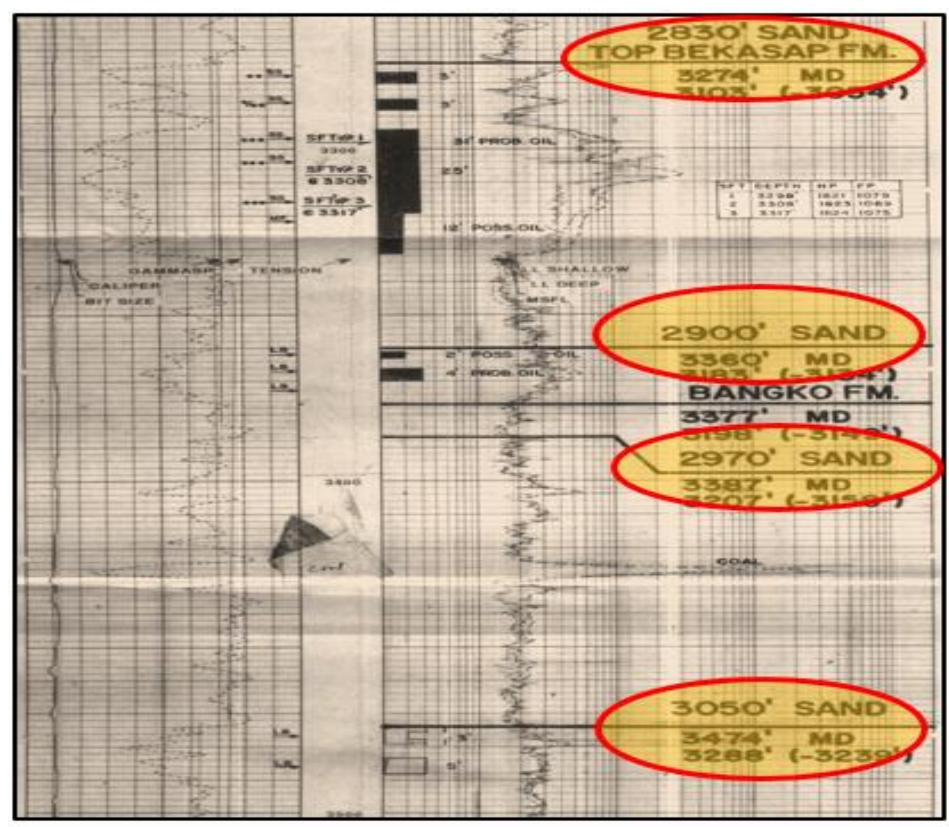

Gambar 7 Marked Log Sumur BA\#147

Sumur BA\#147 merupakan sumur directional. Dan untuk arah lintasan pemboran berdasarkan arah mata angin ataupun tampak samping digambarkan pada Gambar 8 dan Gambar 9.

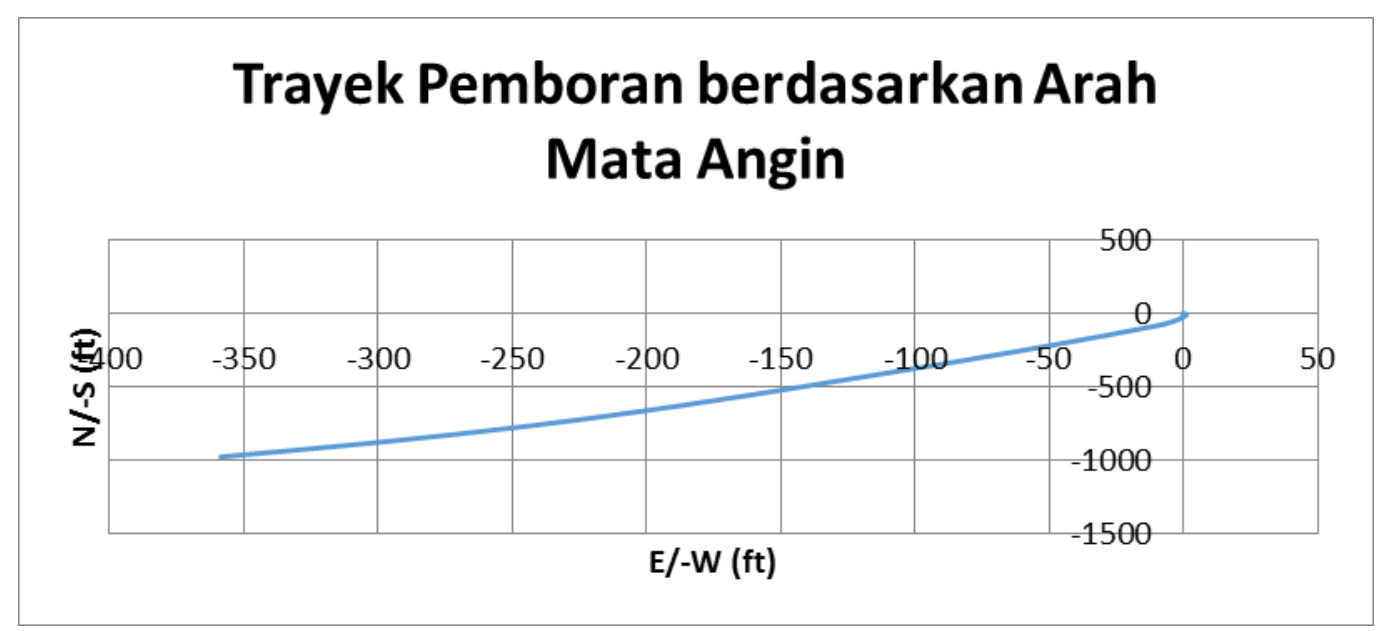

Gambar 8 Trayek pemboran berdasarkan arah mata angin (tampak atas) 


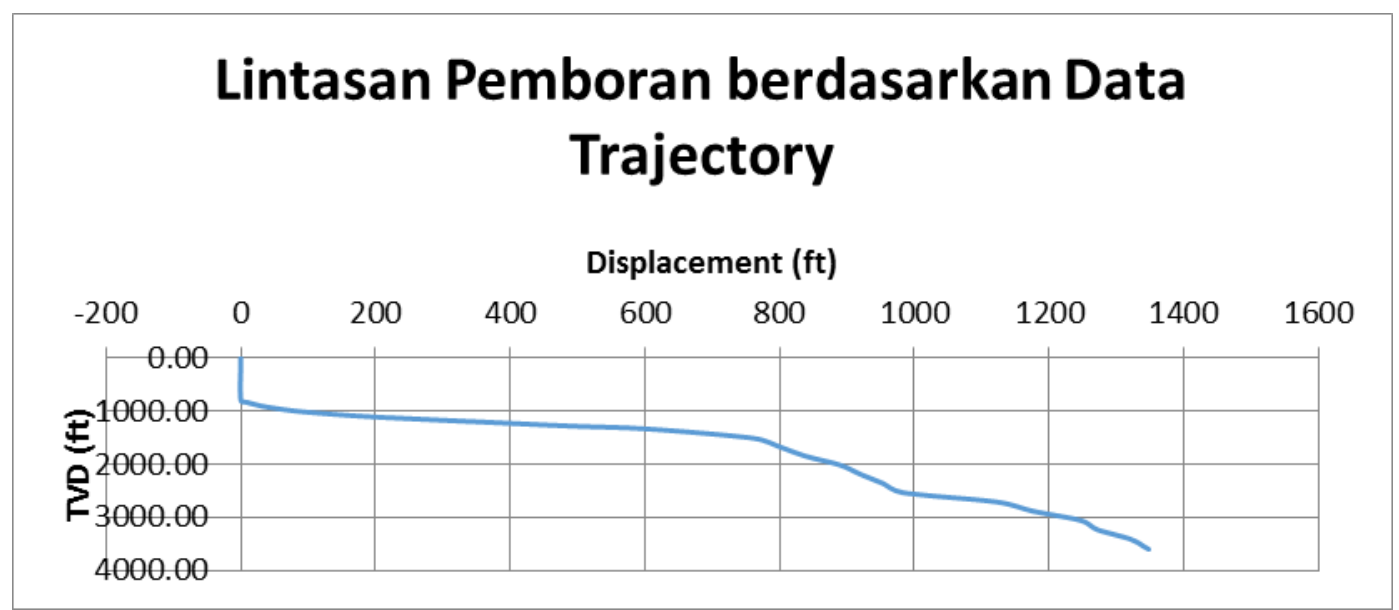

Gambar 9 Lintasan pemboran berdasarkan data trajectory (tampak samping)

Sebelum melakukan pekerjaan workover pada sumur tertentu, perlu diperhitungkan serta dipertimbangkan cadangan yang masih tersisa (Remaining Reserve) di lapisan reservoir pada sumur yang akan dilakukan workover tersebut, apakah masih berpotensi tinggi apabila dilakukan pekerjaan workover serta diproduksikan.

Untuk masing-masing nilai OOIP, NP, dan Remaining Reserve untuk setiap lapisan reservoir pada sumur BA\#147 yang berproduksi sejak tahun 2001 hingga tahun 2014 dapat dilihat pada tabel di bawah ini:

Tabel 1 OOIP, Reserve, Np, dan RR Setiap Lapisan Reservoir

\begin{tabular}{llll}
\hline \multirow{2}{*}{ Data Reservoir Dan Fluida } & \multirow{2}{*}{ Satuan } & \multicolumn{2}{c}{ Lapisan Reservoir } \\
\cline { 3 - 4 } & & $\mathbf{2 8 3 0}$ ' SD & $\mathbf{2 9 0 0}$ ' SD \\
\hline Area, Reservoir & ACRES & 17 & 17 \\
\hline Net Pay & FT & 43 & 6 \\
\hline Porosity & $\%$ & 26 & 28 \\
\hline Saturation, Water & $\%$ & 25 & 25 \\
\hline Formation Volume Factor & RB/STB & 1,078 & 1,078 \\
\hline OOIP & STB & 1.053 .984 & 158.380 \\
\hline Net Production & Bbl & 474.836 & 135.181 \\
\hline Remaining Reserve & STB & 579.148 .70 & 23.199 \\
\hline
\end{tabular}


Berdasarkan Tabel 1, sumur BA\#147 masih memiliki Remaining Reserve yang cukup banyak terutama pada lapisan reservoir Bekasap 2830' Sand'. Sedangkan Bekasap 2900' Sand adalah lapisan reservoir yang memiliki nilai Remaining Reserve paling rendah.

Sehingga lapisan reservoir Bekasap 2830' Sand yang paling berpotensi ekonomis untuk diproduksikan. Sumur BA\#147 telah memproduksikan minyak sejak tahun 2001 - 2014 sebesar 610.017 bbl. Namun, disepanjang periode tahun 2013 - 2014 terjadi peningkatan produksi air yang signifikan. Ditandai dengan meningkatnya harga Water Cut hingga 99\% dan penurunan produksi minyak hingga 8.05 bopd seperti yang terlihat pada Gambar 10 dan Gambar 11.

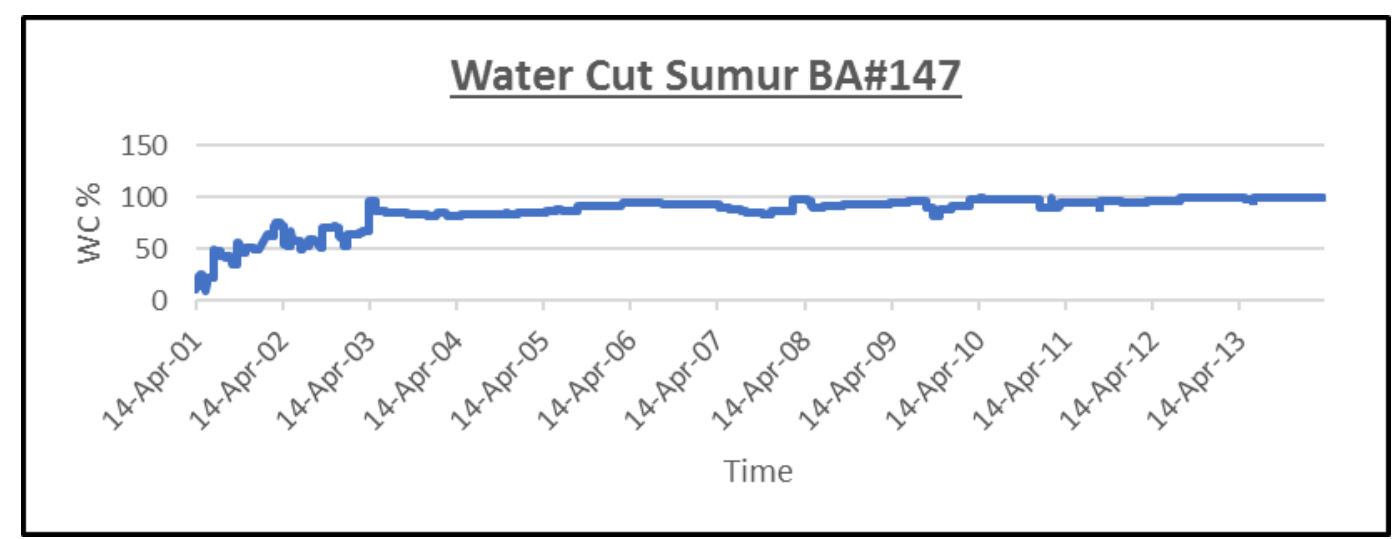

Gambar 10 Grafik peningkatan water cut

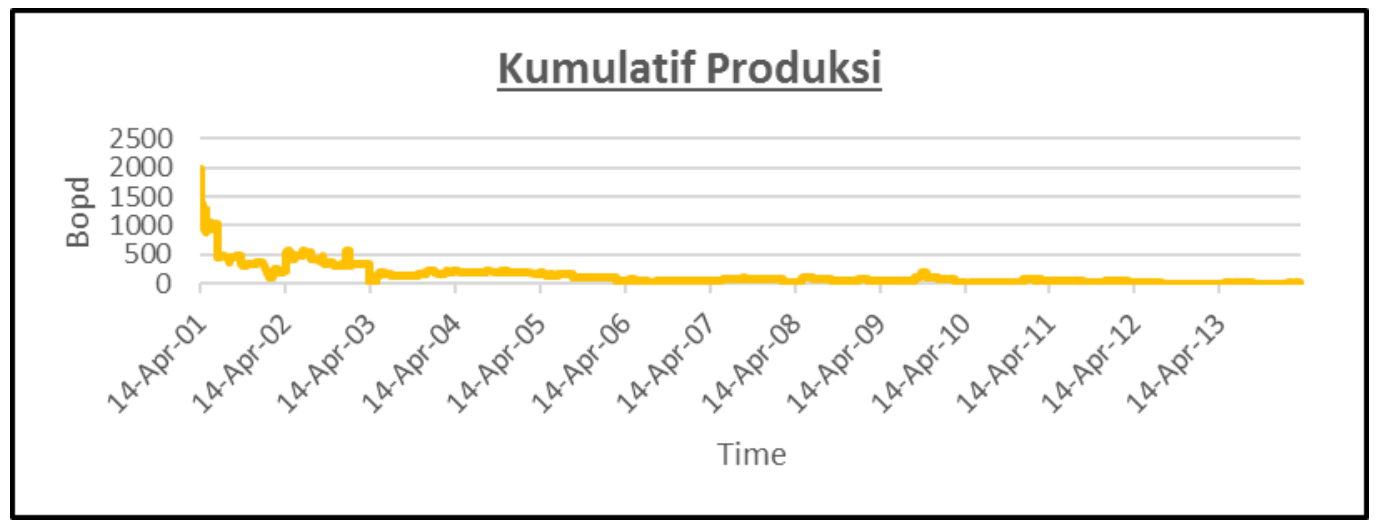

Gambar 11 Grafik penurunan produksi minyak

Berdasarkan hasil interpretasi CBL inital (Gambar 4.2), CBL tidak merepresentasikan adanya kualitas bonding cement yang buruk dengan dihasilkan nilai amplitudo sekitar $10 \mathrm{mv}-15 \mathrm{mv}$. Akhirnya $P E$ field memprediksi kemungkinan terjadinya channeling atau terdapatnya liquid microannulus pada bonding semen dibelakang casing. Karena ditinjau dari remaining reserve masih memiliki potensi yang ekonomis untuk diproduksikan. Sehingga pada 01 April 2014 dilakukan pekerjaan Run USIT Log untuk mengevaluasi bonding cement dan casing pada gambar 7. 


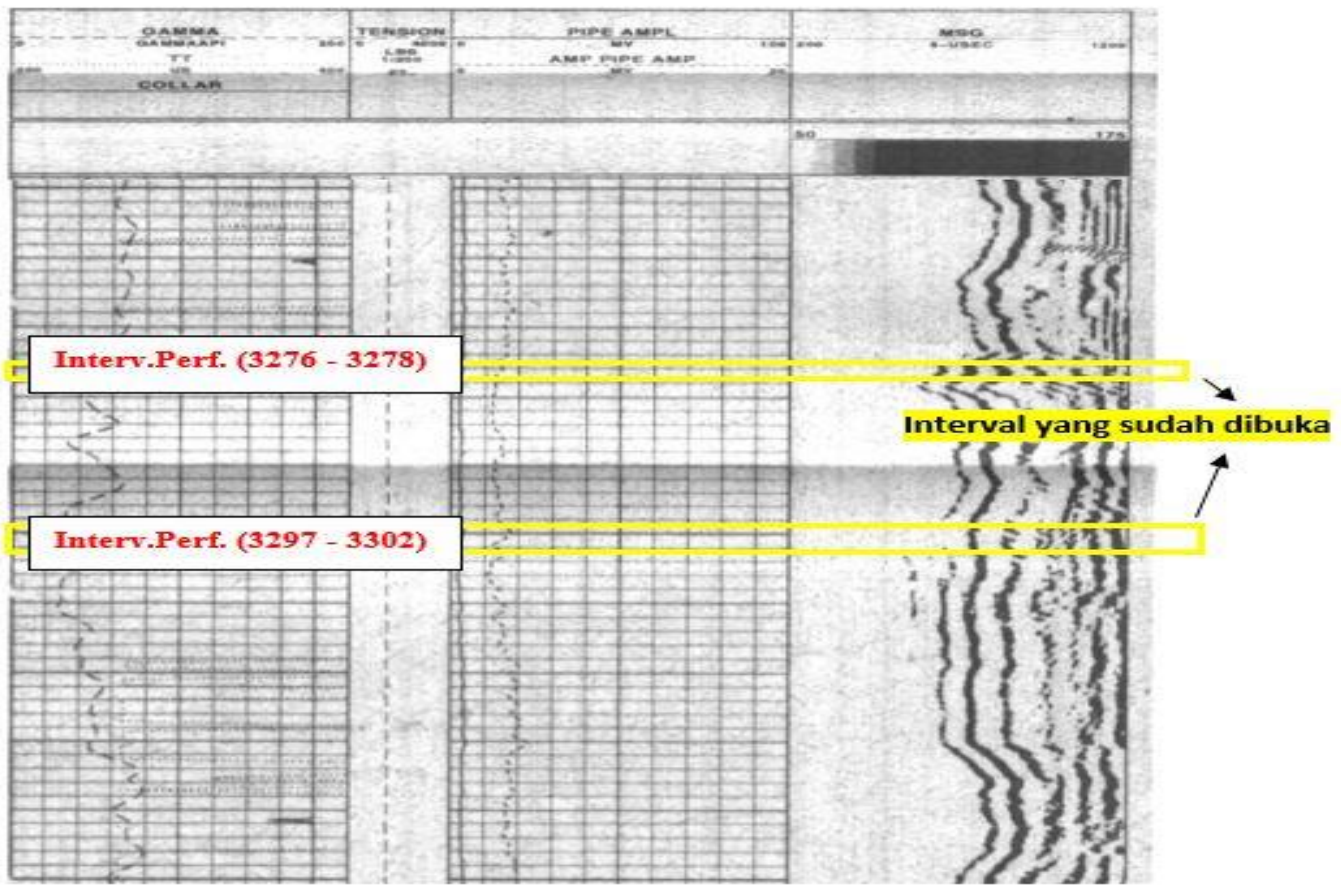

Gambar 12 Cement Bond Log Initial

\section{Hasil Interpretasi USIT Log Awal}

USIT log di run dari kedalaman 3100 - 3490. Pengamatan kualitas bonding cement akan dilakukan disekitar kedalaman ketiga interval perforasi, yaitu interval perforasi 3276 - 3278, 3297 - 3302, dan $3307-3311$

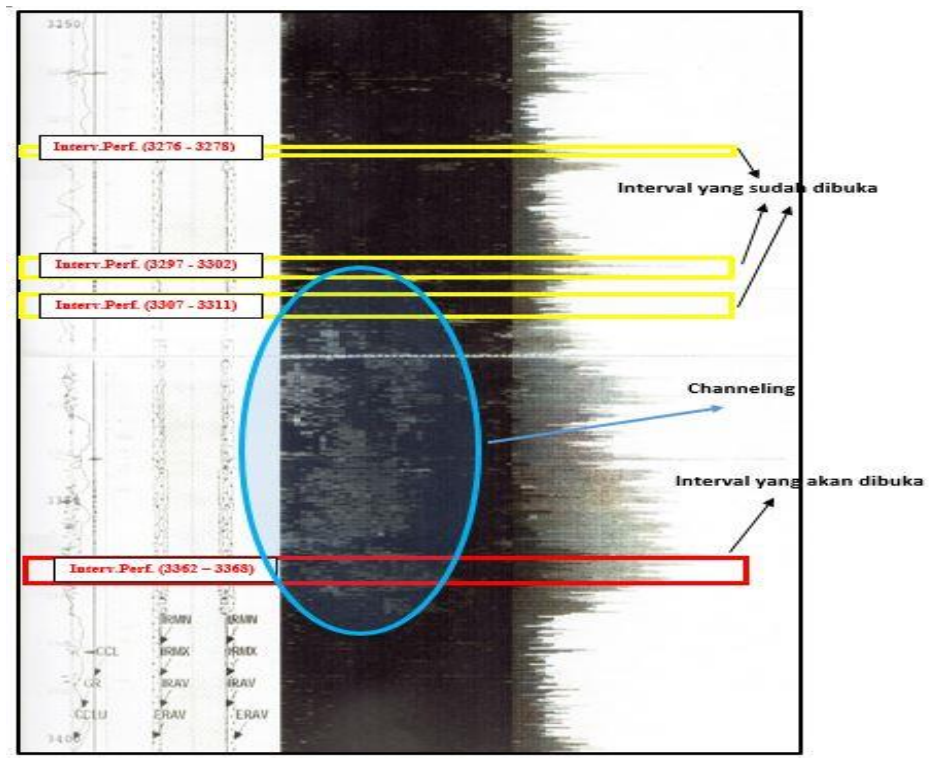

Gambar 13 Hasil Interpretasi USIT Log Awal 
Berdasarkan hasil interpretasi pada Gambar 4.3, USIT log menampilkan image bonding cement secara menyeluruh dan ditemukan kualitas bonding semen yang buruk membentuk gerowong (channeling) pada kedalaman 3300' - 3380'. Hasil rekaman USIT log yang buruk pada kedalaman tersebut sehingga perlu dilakukan squeeze cementing untuk memperbaiki hasil bonding cement sumur tersebut.

\section{Design Squeeze Cementing}

Data injectivity test diperlukan dalam melakukan pekerjaan squeeze cementing untuk menentukan jenis formasi loss, moderate dan tight. Untuk menentukan design cement yang digunakan, dan tekanan pemompaan bubur semen nantinya, agar mendapatkan hasil squeeze yang bagus.

Ada beberapa data yang digunakan untuk melakukan perhitungan squeeze cementing job, data-data ini dapat dilihat pada Tabel 2

Tabel 2 Data Injectivity Test Pada Sumur BA\#147

\begin{tabular}{llllll}
\hline No Sumur & Squeeze Interval & \multicolumn{3}{c}{ Injectivity Test } & \multirow{2}{*}{ Profil } \\
\cline { 3 - 5 } & & & Pressure (psi) & Rate (bpm) & Vol (bbl) \\
\hline BA\#147 & $3276^{\prime}-3376^{\prime}$ & 850 & 1.5 & 20 & moderate \\
& $(4$ interval) & & & & \\
\hline
\end{tabular}

Berdasarkan Tabel 2 dapat dilihat bahwa jenis formasi adalah moderate. Tekanan pemompaan sebaiknya berada dibawah tekanan injectivity, hal ini dimaksudkan untuk menghindari terjadinya perekahan formasi oleh bubur semen dan menghindari terjadinya lost circulation (semen masuk ke formasi). Bubur semen mempunyai densitas yang lebih besar. Untuk itu perlu dilakukan perhitungan bubur semen sebelum menjalankan squeeze cementing job.

Pada pekerjaan squeeze cementing ini dilakukan dengan menggunakan metode open ended dimana estimate top of cement (TOC) berada $50 \mathrm{ft}$ di atas top perforasi. Diketahui data sumur sebagai berikut :

Top perforation $\quad: 3276 \mathrm{ft}$

Bottom perforation : $: 3311 \mathrm{ft}$

OE tubing $\quad: 3381 \mathrm{ft}$

Casing 7 in $23 \mathrm{lbm} / \mathrm{ft} \quad: 0.0394 \mathrm{bbl} / \mathrm{ft}$

Cement slurry/hole : 0.25 cuft/hole

Yield cement $\quad: 1.15 \mathrm{cuft} / \mathrm{sack}$

Densitas slurry $\quad: 15.8 \mathrm{ppg}$

SPF $: 5$

Total Hole : 50 holes

a. E. TOC $=50 \mathrm{ft}$ di atas top perforated

$$
\begin{aligned}
& =3276-50 \mathrm{ft} \\
& =3226 \mathrm{ft}
\end{aligned}
$$

b. Cement In Casing (CIC)

CIC =Casing Capacity 7 " $\mathrm{x}$ (OE Tubing - Est. TOC)

$=0.0394 \mathrm{bbls} / \mathrm{ft} \times(3381-3226)$ 
$=6.10 \mathrm{bbls}$

c. Cement In Formation (CIF)

$\mathrm{CIF}=$ Cement Slurry/Hole $\mathrm{x}$ Total Hole $\mathrm{x} 0.1781 \mathrm{bbl} / \mathrm{cuft}$

$=0.25 \mathrm{cuft} / \mathrm{holex} \times 55$ hole $\times 0.1781 \mathrm{bbl} / \mathrm{cuft}$

$=2.45 \mathrm{bbls}$

d. Total cement slury

$$
\begin{aligned}
& =\mathrm{CIC}+\mathrm{CIF} \\
& =6.10 \mathrm{bbls}+2.45 \mathrm{bbls} \\
& =8.5 \mathrm{bbls}
\end{aligned}
$$

e. Jumlah cement yang dibutuhkan

$$
\begin{aligned}
& =\frac{\text { Total Slurry } x 5.615^{\text {cuft } / \mathrm{bbl}}}{\text { Yield Point }} \\
& =\frac{8.5 \mathrm{bbl} x 5.615^{\text {cuft } / \mathrm{bbl}}}{1.15^{\mathrm{cuft} / \mathrm{sack}}} \\
& =42 \mathrm{sack}
\end{aligned}
$$

f. Air bersih yang dibutuhkan

$$
\begin{aligned}
\text { FW } & =\text { Jumlah semen } \times \frac{4.94 \mathrm{gal} / \mathrm{sack}}{42 \mathrm{bbl} / \mathrm{sack}} \\
& =42 \mathrm{sack} \times \frac{4.94 \mathrm{gal} / \mathrm{sack}}{42 \mathrm{bbl} / \mathrm{sack}} \\
& =5 \mathrm{bbl}
\end{aligned}
$$

g. Fracture pressure = gradient fracture $\mathrm{x}$ top perforation

$$
\begin{aligned}
& =0.8 \mathrm{psi} / \mathrm{ft} \times 3276 \\
& =2620.8 \mathrm{psi}
\end{aligned}
$$

h. Total additif yang digunakan

- Hallad - $344 \mathrm{~L}=21$ gals Jenis additif ini digunakan untuk mencegah terjadinya fluid loss, yaitu hilangnya fasa liquid semen kedalam formasi. Dengan menambahkan jenis additif ini kandungan cairan pada suspensi semen akan terjaga, sehingga suspensi semen tidak akan kekurangan air.

- CFR (Cement Friction Reducer) - 2 L = 10.5 gals

Jenis additive ini digunakan untuk memperkecil viskositas suspensi semen.

- $\quad \mathrm{HR}-5=5.04$ gals

Jenis additif ini dikategorikan kedalam jenis additif cement retarder. Additif ini berfungsi untuk memperlambat proses pengerasan semen, sehingga suspensi semen mempunyai waktu yang cukup untuk mencapai kedalaman target yang diinginkan.

- D air $-2 \mathrm{~L}=16.8$ gals

Jenis additif ini digunakan untuk mencegah hilangnya tekanan pemompaan.

Sebelum dilakukan squeeze cementing di ketiga interval perforasi yang sekaligus mengimprove bonding cement tersebut, telah dilakukan run CHFR (cased hole formation resistivity) yang bersamaan dengan run USIT awal. Yang bertujuan untuk mendapatkan informasi tambahan mengenai oil 
resistivity atau remaining oil reserve berdasarkan hasil CHFR. Akhirnya $P E$ field memutuskan untuk melakukan perforasi pada lapisan bekasap 2900' sand di kedalaman 3362' - 3368'. Dan hasilnya didapatkan seperti yang terlihat pada Gambar 4.10 dan Gambar 4.11.

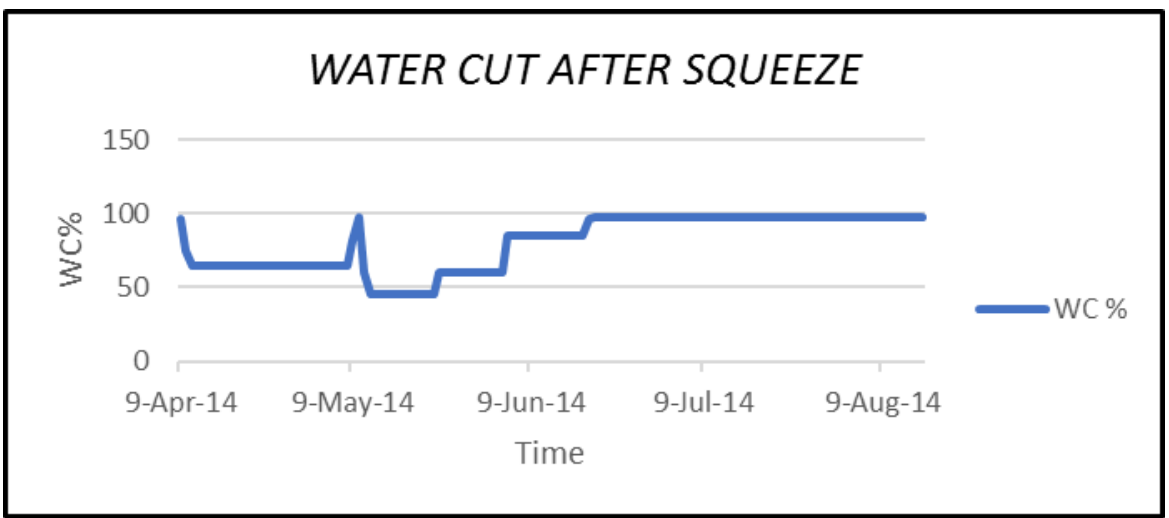

Gambar 14 Harga Water Cut Setelah Squeeze Cementing dan Penambahan Perforasi

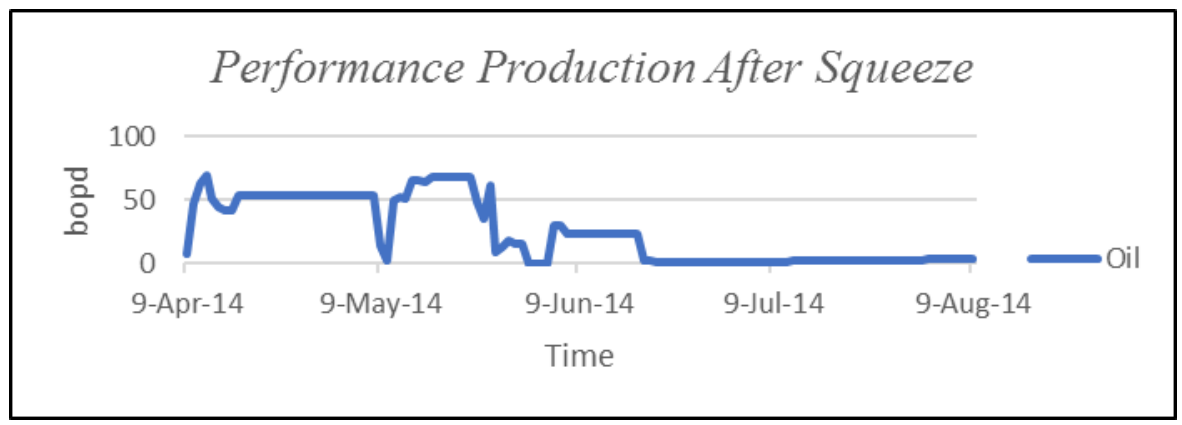

Gambar 15 Performance Produksi Setelah Squeeze Cementing dan Penambahan Perforasi

Berdasarkan Gambar 14, terjadi penurunan harga water cut hingga 65\% dan peningkatan produksi minyak hingga 65.45 bopd yang mengindikasikan keberhasilian dari pekerjaan squeeze cementing. Namun keadaan tersebut hanya bertahan selama 4 bulan. Harga water cut kembali meningkat secara signifikan hingga 99\% dan produksi minyak menurun hingga 3.32 bopd pada 15 Agustus 2014. Berdasarkan perhitungan remaining reserve di lapisan kedalaman tersebut masih ekonomis untuk diproduksikan. Akhirnya PE field merencanakan untuk melakukan stimulasi sumur BA\#147 dengan menggunakan COA (Co-Ascender) + LS (Lock Seal) pada interval perforasi 3362' - 3368'. Berdasarkan data swab test didapatkan oil rate sebesar 180 bbl dengan harga water cut yang masih cukup tinggi yaitu $98 \%$.

\section{Hasil Interpretasi USIT Log Kedua}

Untuk meningkatkan kembali produksi minyak, dilakukan reperforated pada lapisan Bekasap 2900' SD dikarenakan masih memiliki potensi cadangan yang masih ekonomis. Reperforated dilakukan pada interval kedalaman 3276' - 3278' dan 3294' - 3311'. Untuk memastikan bahwa interval kedalaman tersebut aman untuk direperforated, dilakukan run USIT Log yang kedua pada 01 Oktober 2014 untuk mengevaluasi hasil squeeze cementing sebelumnya dan memastikan bahwa kualitas bonding cement 
disekitar interval yang akan di perforasi aman atau tidak ada terjadi komunikasi dengan lapisan di atas maupun dibawahnya.

Run USIT log dilakukan dimulai dari kedalaman 2700' - 3900'. Pengamatan kualitas bonding cement akan dilakukan disekitar interval kedalaman yang akan di reperforated yaitu 3276' - 3278' dan 3294' $3311^{\prime}$.

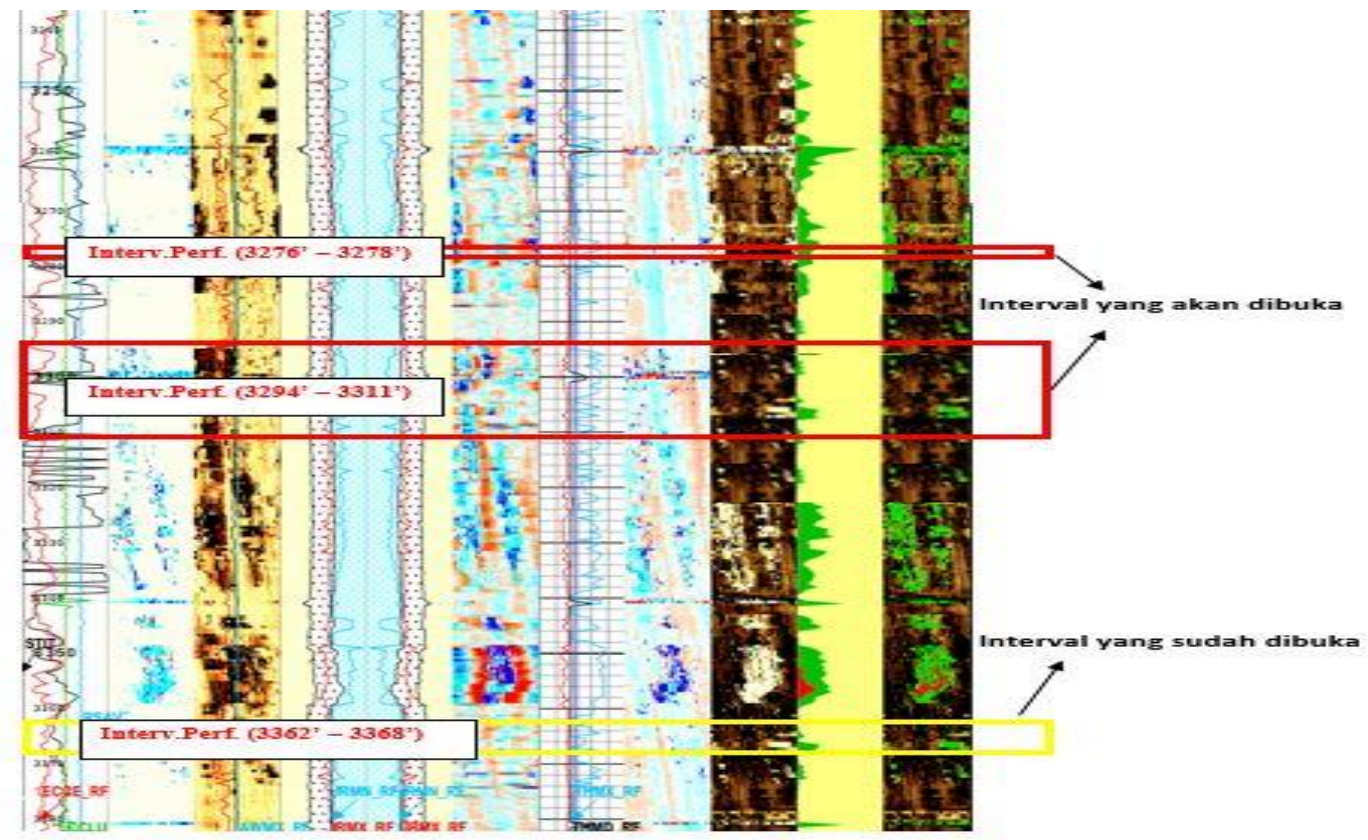

Gambar 17 Hasil Interpretasi USIT log Kedua

Berdasarkan hasil interpretasi USIT log kedua, bahwa kualitas bonding cement disekitar interval yang sudah dibuka yaitu 3362' - 3368', didominasi oleh impedance image berwarna coklat kehitaman yang mengindikasikan kualitas bonding cement yang baik. Begitu juga dengan kualitas bonding cement di sekitar 2 interval perforasi yang akan dibuka yaitu 3276' - 3278' dan 3394' - 3311' didominasi oleh impedance image berwarna coklat ke hitaman. Meskipun dari hasil swab test didapatkan harga water cut yang cukup tinggi (98\%), ketiga interval perforasi tersebut tetap diproduksikan karena masih terdapat remaining reserve yang masih prospek untuk diproduksikan yaitu 98.215.06 stb pada Bekasap 2830' SD dan 19.183 stb pada Bekasap 2900' SD. Berdasarkan gambar 18 hasil korelasi log di bawah dapat dinyatakan bahwa pekerjaan squeeze cementing berhasil walaupun ada beberapa bonding cement yang termasuk dalam kualitas sedang (partial bond), tetapi tetap aman untuk dilakukan perforasi. 


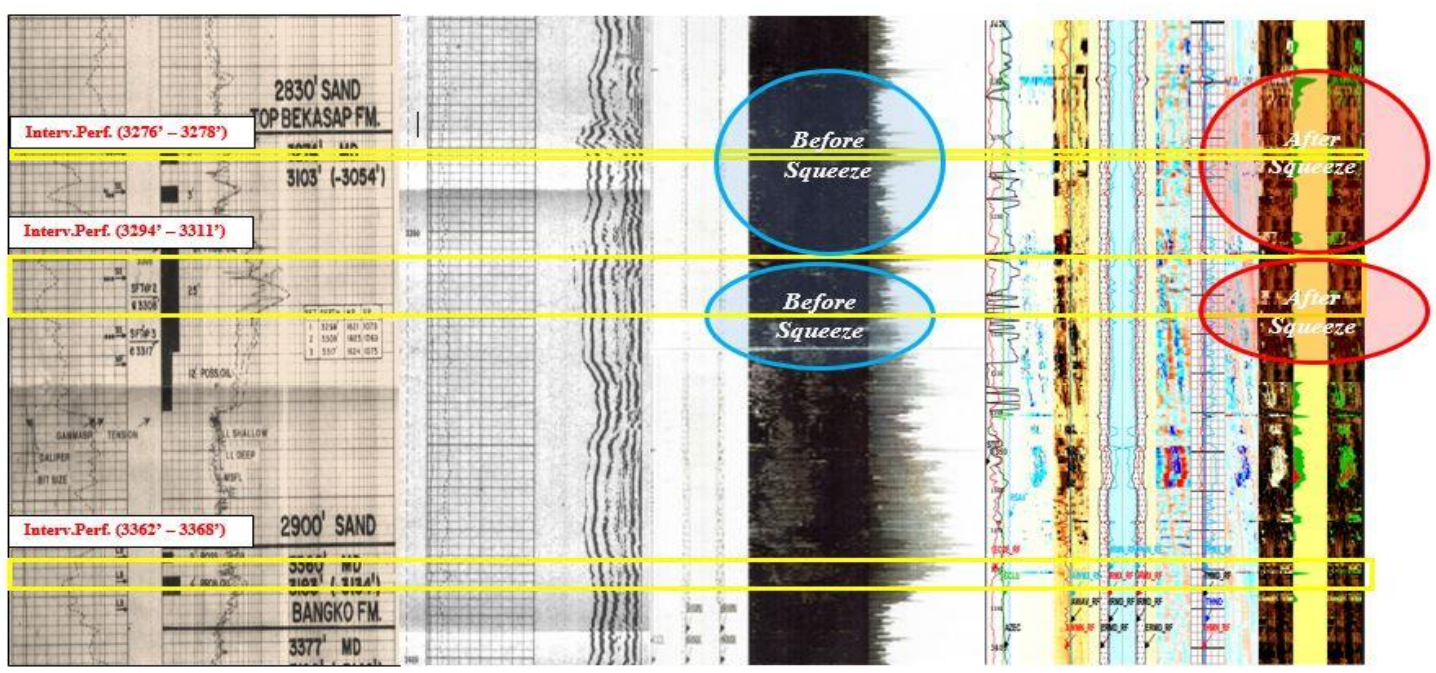

Gambar 18 Korelasi marked log, CBL initial, USIT log awal dan USIT log kedua

\section{KESIMPULAN}

Kesimpulan yang didapatkan dari penelitian ini adalah sebagai berikut:

1. Berdasarkan hasil evaluasi kualitas bonding cement di sumur BA\#147 dengan menggunakan USIT log, didapatkan hasil kualitas bonding cement yang buruk (channeling) yaitu pada interval $3300-3380$ (50 ft).

2. Design squeeze cementing yang digunakan untuk memperbaiki bonding cement sumur BA\#147 dibutuhkan 8.55 bbls slurry cement, 1.27 bbl additif dan maximum squeeze pressure 586 psi dengan teknik penyemenan menggunakan teknik bradenhead (open ended).

\section{DAFTAR PUSTAKA}

Andrew, et al. (2000). Cement evaluation with the ultrasonic imager p. 10-19. Schlumberger.

King, G. E. (1996). An introduction to the basics of well completions, stimulations and workovers (ed. $\left.2^{\text {nd }}\right)$. Tulsa, Oklahoma: Snad Springs.

Pal, N. \& Ahmed, M.M. (2006). Value addition using cement evaluation by ultra sonic imaging tool in upper assam oil fields p.554-558. Paper presented $6^{\text {th }}$ International Conference \& Exposition on Petroleum Geophysics.

Soeharto, S. (2012). Open hole formation evaluation and case hole log interpretation p.341-353. Yogyakarta : Kopum IATMI.

Timonin, A., Lungershausen, D., \& Kravets, P. (2004). Microannulus and cement evaluation: effectiveness of cement evaluation using ultrasonic technologies in wells with microannulus between casing and cement sheath. Presented at the SPE Annual Technical Conference and Exhibition, Kazakhtan, 12-14 November.

Nelson, E.B. (1990). Well Cementing. Amsterdam: Elsivier.

Paynere, J. (2003). What to look for in USIT log. Texas: Schlumberger Educational Services.

Rubiandini, R. (2012). Teknik Operasi Pemboran. Bandung: Penerbit ITB. 